\title{
Doğu Anadolu'da Kara Koyunlu- Timurlu Mücadelesi ve Eleşkirt Meydan Muharebesi
}

\section{Erol Keleş*}

\section{Özet}

Timur'un batı seferleri sonucunda Azerbaycan ve Doğu Anadolu toprakları Kara Koyunlu hâkimiyetinden çıkmıştı. Timur'un ölümünden sonra vasiyet üzere bahsi geçen toprakların sahibi olan Timur'un torunu Ebu Bekir ile diğer torunu Ömer Mirza arasındaki sürtüşmeler Kara Koyunlu hükümdarı Kara Yusuf tarafından ziyadesiyle değerlendirildi. 1407 ve 1408'de Timur'un torunu Ebu Bekir'e karşı kazandığı iki büyük zafer sonucunda Doğu Anadolu, Azerbaycan ve Irak-ı Acem bölgeleri Kara Koyunlu hâkimiyeti altına alındığı gibi Kara Koyunlu devleti de kesin olarak kurulmuştu.

Böylece Timur'un ölümünden kısa bir süre içinde kurmuş olduğu imparatorluğun batı topraklarının büyük kısmı elden çıkmış oldu. Bu büyük zaferlerin hemen ardından Kara Yusuf bir dönem kader arkadaşlığı yaptığı Ahmet Celayir'i yenerek ortadan kaldırmış ve illhanlı mirasının da varisliğini Oğlu Pir Budak'a kazandırmıştı. Türkmen Yusuf Bey'in önce Timurlu mirzalarını yenmek ve ardından Celayirli Ahmet'i ortadan kaldırmak suretiyle Azerbaycan'a hâkim olunca, Timurluların tehlikeli bir komşusu haline gelmişti. Şahruh ise doğuda durumunu sağlama almış ve artık Kara Koyunlularla yakından ilgilenmenin zamanı geldiğini düşünmeye başlamıştı. Evvela Kara Yusuf tarafından öldürülen abisi Miranşah’ın intikamının alınması gerekiyordu. Diğer taraftan İran Moğollarının merkezi durumundaki bölgenin sembolik önemi vardı. Timur'un Sultaniye'yi fethinden itibaren hanedan ilhanlıların mirasını devraldığı iddiasındaydı. Bu Şahruh için önemliydi. Çünkü kendisi de İlhanlı ünvanlarını benimsemiş ve İran'da Moğol geleneklerini uygulayan Gazan Han'ı taklit ediyordu. Kazvin ve Sultaniye gibi ticari önemi olan şehirleri ise kendi topraklarının bir parçası sayıyordu.

Bölgede tek hâkim durumuna yükselen Kara Yusuf, bu duruma son vermek isteyen Şahruh'un karşısına çıkmaya hazırlanırken vefat edecektir. Ancak Kara Yusuf'un oğullarının hayattayken bölgedeki hâkimiyetini tehlike altında

\footnotetext{
Innönü Üniversitesi Sosyal Bilimler Enstitüsü Genel Türk Tarihi Ana Bililm Dalı, erlkls44@hotmail.com. (ORCID ID: 0000-0002-1717-212X)

(Makale Gönderim Tarihi: 18.07.2017, Makale Kabul Tarihi: 21.10.2017)
}

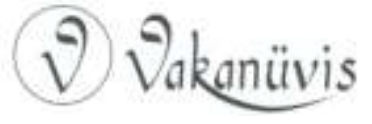


hisseden Şahruh, onları ortadan kaldırmadan bunun mümkün olamayacağını biliyordu. Bu sebeple geri dönmeden Kara Koyunlulara büyük bir darbe indirmek için hazırlıklara başlarken İskender Mirza ve kardeşi İspend Mirza ise birleşerek Eleşkirt civarında savaş vaziyeti alacaklardır. Şahruh savaşı kazanmasına rağmen Mirzaları ele geçiremeyecek ve Kara Koyunlular Timurlular için tehlike olmaya devam edecektir.

Anahtar Kelimeler: Timur, Kara Koyunlular, Türkmenler, Şahruh, Eleşkirt

\title{
Qara Qoyun-Timurid Struggle in the Eastern Anatolia and the Battle of Valasjird
}

\begin{abstract}
As a result of Timur's west wars, Azerbaijan and Eastern part of Anatolia's lands had been lost from the dominance of Qara qoyunlu. After Timur's death the contradictions between Timur's grandsons, Abubakr and Omar Mirza, the owner of the mentioned lands were deeply evaluated by the Emperor of Qara qoyunlu. In 1407 and 1408, as a result of two big viktories against Timur's grandson Abu Bakr, both Eastern Anatolia, Azerbaijan and Iraq regions were dominated by Qara qoyunlu goverment was certainly estabilished.

Thus most of the western parts of the Empire lands that Timur estabilished a short time before his death were lost. Then Qara Yusuf gave the Ilkhanid heritage to his son Pir Budak and mad ehim gain the heir. Most parts of the western lands that were established by Qara Yusuf beated Ahmad Djalair with whom he once had made fate friendship. Turkoman Yusuf first Timur remainders and then wiped out Djalair Ahmad. As a result of this he gained Azerbaijan. So he became a dangerous enemy of Timurs. Shah-Ruh guaranteed his situation in the East and he thought it's high time. That he dealt with the Qara qoyunlu. First of all it was obligatory to take the revenge of his brother Miran-Shah who was killed by Qara Yusuf. On the hand the area which is the centre of the Persian Mongol was of great importance symbolically since the Timur's conquest of Sultaniye the Emperor claimed that he gained the heritage of Ilkhanids. This was importand for Shah-Ruh. Because he himself adopted the Ilkhanid title and imitating the Ghazan Han who was applying the traditions of Mongol in Persia. He assumed that Kazvin and Sultaniye which has great importance on trading as on of his own lands.
\end{abstract}

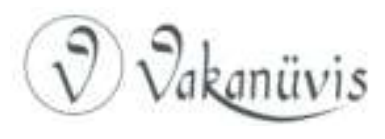


Qara Yusuf who was considered the only leader at that area died while he was preparing to face the Shah-Ruh troops. However Shah-Ruh who felt that Kara Yusuf's sons' dominance in the area while he was alive was in danger knew that this it was impossible without eliminating them. Thus, in order to break down Qara qoyunlu before going back Shah-Ruh started preparations on the other side Iskandar Mirza had taken the war position in cooperation. Although Shah-Ruh won the war, he arrested Mirzas and Qara qoyunlu would keep on being danger for Timurs.

Keywords: Timur, Qara qoyunlu, Turkomans, Shah-Ruh, Valasjird.

XIV. yüzyılın sonlarından başlayıp XV. yüzyılın ilk çeyreği boyunca devam edecek olan Kara Koyunlu-Timurlu mücadelesi özellikle Doğu Anadolu'da siyasi, sosyal ve kültürel açıdan derin izler bırakmıştır. Bu konuda ülkemizde pek çok çalışma yapılmış olmasına rağmen konunun bu yönü üzerinde ciddi bir şekilde durulmadığı tespit edilmektedir. Çünkü bahse konu bu çalışmalar daha çok Timurlu-KaraKoyunlu mücadelesinin askeri ve siyasi sonuçlarını ele almaktadır. Hâlbuki bu mücadeleler bölgenin sosyo-kültürel yapısının teşekkülünde de önemli bir rol oynamıştır. Dolayısıyla bu çalışmayla sözü edilen meseleye bir ölçüde ışık tutulacağı düşünülmektedir. Diğer taraftan konuyla ilgili çalışmaların başvurmadığı ya da çok dikkate almadığı Doğu Anadolu'da bulunan Ermeni manastırlarında kaleme alınan ve olayların bizzat görgü şahidi olan rahiplerin yazmalarından bu çalışmada ziyadesiyle istifade edilip konuya yeni bir bakış açısı geliştirilmeye çalışılacaktır.

İlhanlı hükümdarı Ebu Said Bahadır Han'ın ölümü (1335) üzerine Moğol noyanlarının iktidar mücadelesine girişmeleri ${ }^{1}$ Sutayların hizmetinde bulunan Kara Koyunluların siyasi alanda önünü açmıştır. Nitekim bölgede güçlü bir merkezi otoritenin yokluğu ve daha sonraki dönemde ise Timur istilalarıyla artan istikrarsızlıklar başlıca

\footnotetext{
${ }^{1}$ Bu mücadeleler hakkında bkz., Bertold Spuler, Iran Moğolları (Syaset, idare ve Kültür, IIhanlılar Devri 1220-1350), (nşr. C. Köprülü), Ankara 2011, s.144-154; F. Sümer, "Anadolu'da Moğollar", SAD I, Ankara 1970, s.95-143.
}

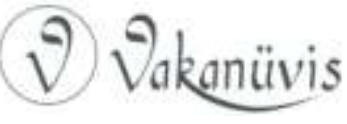


Türkmen boy ve birliklerinin ${ }^{2}$ Kara Koyunlular etrafında bütünleşmesini sağlayacaktır. ${ }^{3}$ Soylarını Oğuz Han ahfadından Deniz Han'a dayandıran Kara Koyunlular ${ }^{4}$ Türkistan'ın Gazgırt bölgesinden Azerbaycan'a, oradan da Bitlis ve havalisine göç etmiştir. ${ }^{5}$ Ancak ne zaman geldikleri konusu tartışmalıdır. Tarih-i Türkmaniye'nin verdiği bilgilere göre otuz bin çadırdan oluşan Kara Koyunlular, Cengizhan'ın hücumu üzerine Türe Bey adıyla bilinen liderlerinin idaresinde Türkistan'dan Maveraünnehr'e, oradan da İran üzerinden Doğu Anadolu'ya gelerek yerleşmiştir. ${ }^{6}$

Kara Koyunlulara ait tarihi bilgiler, reisleri Bayram Hoca (ölümü 1380) ile alakalı olarak 1365-66 yılında başlamaktadır. Bu dönemde bölgedeki Türkmenler üzerinde hâkimiyet sağlayan Hüseyin Beğ'in nezdinde büyük itibarı olan Bayram Hoca'nın bir süre sonra onu öldürüp yerine geçtiği anlaşılmaktadır. ${ }^{7}$ Kısa sürede hâkimiyet alanını genişleten Bayram Hoca, Erzurum'dan Musul'a kadar uzanan alanda bir beylik kurmak suretiyle Doğu ve Güneydoğu Anadolu'nun uç bölgelerinde Türkmen hakimiyetini tesis etmiştir. ${ }^{8} 1380$ 'de vefat ettiği anlaşılan Bayram Hoca'nın yeri kardeşi ya da yeğeni olan Kara Mehmet tarafından doldurulacaktır. ${ }^{9}$

\footnotetext{
${ }^{2}$ Bu boy ve topluluklar için bkz. F. Sümer, Kara Koyunlular, Ankara 1992, s.19-32.

${ }^{3}$ Peter B. Golden, Türk Halkları Tarihine Giriş, (nşr. O. Karatay), İstanbul 2012, s.375.

${ }^{4}$ Şükrüllah bu bilgiyi devletin en önemli hükümdarlarından olan Cihan Şah'a dayandırmaktadır. Bkz. Atsız, Üç Osmanlı Tarihi (Oruç Beğ Tarihi, Dastan ve Tevarih-i Al-i Osman, Behcetü't Tevarih), İstanbul 2013, s.203vd; M. Fahrettin Kırzıoğlu, Dede Korkut Oğuznameleri I. Kitap, İstanbul 1952, s.39; Tufan Gündüz, Bozkırın Efendileri (Türkmenler Üzerine Makaleler), İstanbul 2009, s. 66.

${ }^{5}$ Bkz., Devletşah, Tezkire-i Devletşah III, (nşr. Necati Lügal), Ankara 1987, s.457; A. Z. Velidi Togan, Umumi Türk Tarihi'ne Giriş I, İstanbul 1981, s.363; M. F. Kırzıoğlu, Dede Korkut Oğuznameleri I, s.44; F. Sümer, a.g.e, s.35vd.

${ }^{6}$ Bkz. Togan, a.g.e, s.363; M. F. Kırzıoğlu, Dede Korkut Oğuznameleri I, s.44; Sümer, a.g.e, s.35vd.

${ }^{7}$ Sümer, a.g.e, s.108.

8 Bkz. H. Dursun Yıldız, Makaleler III, (nşr. E. S. Yalçın vd), Ankara 2007, s.173.

9 Bayram Hoca ile ilgili son bilgi onun ölüm tarihine aittir. İbn Hacer, 1380 yılı hadiseleri arasında Musul hâkimi olarak tanıdığı Bayram Hoca'nın öldüğünü ve yerine kardeşi Berdi Hoca'nın geçtiğini bildirmektedir. [Bkz. F. Sümer, a.g.e, s.44vd.] A. Z. V. Togan ise Kara Mehmed'i, Bayram Hoca'nın oğlu olarak gösterir. Bkz., Togan, a.g.e, s.363.
}

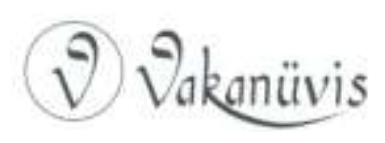


1386 yılında Batı İran'ı zapt etmiş olan Timur aynı senenin kışında Karabağ'da bulunuyor ${ }^{10}$ ve Doğu Anadolu'nun istilasına hazırlanıyordu. ${ }^{11}$ Timur bu istilaya hazırlanırken Kara Mehmed'i hac kafilelerine ve ticaret kervanlarına tecavüz etmekle itham ediyordu. ${ }^{12}$ Fakat asıl sebep Kara Mehmed'in Timur'u metbu tanımaması idi. ${ }^{13}$

Timur 1387 yılı baharında Nahçivan'dan kalkarak, ağırlığın Aladağ'da kalmasını emretmiş ve bizzat kendisi de ılgarla ${ }^{14}$ Kara Koyunlular'ın üzerine yürümüştü. Aydın Kalesi de denilen Bayezid (Bugünkü Doğu- Bayezid) kalesine gelen ve Aydın halkının istila önünden kaçarken bırakmış olduğu davarları ordusuna yağma ettiren Timur ${ }^{15}$, buradan Kara Mehmed'in oğullarından Mısır Hoca'nın elinde bulunan Avnik ${ }^{16}$ kalesine erişti. ${ }^{17}$ Timur bu kalenin heybet ve metanetini görerek buranın zaptına girişmedi. ${ }^{18}$ Avnik önünden süratle ayrılan Timur, Erzurum'a varıp bu şehri aynı günde aldı ve oradan

10 Nizamüddin Şami, Zafername, (nşr. Necati Lugal), Ankara 1987, s.122.

${ }_{11}$ Bkz. Yıldız, a.g.e, s.173,174; Sümer, a.g.e, s. 49; İsmail Aka, Timur ve Devleti, Ankara 1991, s. 14; Yaşar Yücel, Timur'un Ortadoğu-Anadolu Seferleri ve Sonuçları (13931402), Ankara 1989, s. 6; M. Kafalı, "Timur", IA XII, s.341.

12 Şami, a.g.e., s.124; Şerefüddin Ali Yezidi, Emir Timur (Zafername), (nşr. Ahsen Batur), İstanbul 2013, s.158; Rene Grousset, Bozkır Imparatorluğu (Attila, Cengiz Han, Timur), (nşr. M. Reşat Uzmen, İstanbul 2010, s.470.

13 Kafalı, a.g.m, s.341.

14 Askeri kuvvet, ordu, birlik.

15 Yezidi, a.g.e., s.158.

16 Avnik'in tarihi oldukça eskiye inmektedir. Urartular'dan kalma çivi yazılı belgeler, yakın zamana kadar kaledeyken şimdi Erzurum Müzesi'ne nakledilmiştir. Med, Pers, Ermen, Part, Sasani, Roma, Bizans devirleri karanlıktır. X. yüzyılda Castrum Abnicum diye geçmektedir. Kafkasya ve Azerbaycan'a giden İslam ordularının üssü idi. Zivin, Micingert ve Ürgümi kaleleri gibi tahkim edilmiş ve asker konulmuştu. Abnik de bu sırada Avnik olmuştur. Ab-ı Nik=Güzel Su anlamındadır. Dede Korkut destanındaki Avnuk Kal'ası, Avnik'e karşılıktır. XIV. yüzyılda Kara Koyunlular'ın Pasın'lardaki gözde kaleleri arasına girmiş, hükümdarlık ailesinden fertlerce yönetilmiştir. Avnik şu anda Erzurum ili, Köprüköy ilçesinde, Güzelsu ismini taşımaktadır. Daha fazla bilgi için bkz. Enver Konukçu, "Kara Koyunlular'ın Avnik Kalesi”, İsmail Aka Armağanı, İzmir 1999, s.37-42.

17 Aziz b. Erdeşir Esterebadi, Bezm ü Rezm, (nşr. Mürsel Öztürk), Ankara 1990, s.417.

${ }^{18} \mathrm{~N}$. Şami bu kalenin pek sarp ve memleketin ortasında vaki olduğunu, Türkmenlerin (Kara Koyunlular) isyan ve serkeşlik ettikleri vakit buraya sığındıklarını ve burayı istinatgâh olarak kullandıklarından bahsetmektedir. Bkz. Şami, a.g.e., s.187.

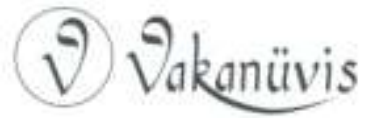


Çapakçur suyu kenarına geldi. ${ }^{19}$ Miranşah bol ganimetler elde etmişse de Kara Mehmed, süratle onun önünden çekilerek, Çapakçur (Bingöl) çevresine gelmiş ve burada sarp geçit ve boğazları tutarak Timur'un üzerine gönderdiği kuvvetleri perişan etmiştir. ${ }^{20}$ Daha sonra Kara Mehmed, Memluklar'ın Malatya valisi Mintaş'ın yanına sığınmıştır. ${ }^{21}$ Bölgedeki Kara Koyunlu hâkimiyetinin geçici de olsa zayıflaması yerel yönetimlerin Timur'a itaatlerini beraberinde getirmiştir. ${ }^{22}$

Kara Mehmed'i ele geçiremeyeceğini anlayan Timur, Muş sahrası istikametini takip ederek Ahlat önüne gelmiştir. ${ }^{23}$ Ahlat'ı ve Adilcevaz'। zapt eden Timur, ağırlığın bulunduğu Aladağ'a yönelmiş ${ }^{24}$ ve burada Abaka Sarayı çayırlığında bir süre oyalandıktan sonra, yeniden Van üzerine yürüdü (1387). ${ }^{25}$ Van kalesinin çok müstahkem olması yüzünden zaptı hiç kolay olmadı. Şehrin hâkimi İzzeddin Şir uzun süre mukavemet etti ise de Timur'a itaat etmek zorunda kaldı. ${ }^{26}$ Kara Mehmet ise Nisan $1389^{\prime}$ da Türkmen emirlerinden Kara/Pir Hasan'la ${ }^{27}$ girdiği bir mücadele sırasında hayatını kaybedecektir. ${ }^{28}$ Onun oğlu Kara Yusuf, bazı Türkmen oymaklarıyla birlikte Kara Koyunluları da etrafında toplamayı başaracaktır. ${ }^{29}$

19 Sümer, a.g.e, s.49.

Yezdi, a.g.e., s.158; T'ovma Metsobets, The History of Tamerlane and His Successors, (nşr. R. Bedrosian), New York 1987 s.12.

21 Refet Yinanç, Dulkadir Beyliği, Ankara 1989, s.28.

22 Şerefhan, Şerefname, (nşr. M. Emin Bozarslan), İstanbul 1990, s.430vd; T'ovma Metsobets, , s.18.

23 Şami, a.g.e., s.186.

24 Timur'un bu esnada katına gelen ve kendisine sadakatle bağlanmış olan Adilcevaz hâkimi Hakan'a Ahlat şehri ve yöresinin idaresini (suyurgal fermude) vermiştir. Bkz. F. Sümer, "Ahlat Şehri ve Ahlatşahlar", Belleten, L/297 (Ankara 1986), s.462.

25 Yezdi, a.g.e., s.159; Sümer, a.g.e, s.51.

26 Metsobets, a.g.e., s. 20vd. Ayrıntılı bilgi için bkz. Şerefhan, a.g.e., s. 107vd.

27 Pir Hasan'ın, Kara Koyunlu ailesiyle akrabalık tesis etmiş olan Sa'adlu kabilesinin reisi olması muhtemeldir. Bkz. M. Fahrettin Kırzıoğlu, Kars Tarihi I, İstanbul 1953, s.470.

28 Ebu Bekr-i Tihrani, Kitab-ı Diyarbekriyye, (nşr. Mürsel Öztürk), Ankara 2001, s.36.

29 Devletşah III, s. 457; i. Hakkı Uzunçarşılı, Anadolu Beylikler ve Akkoyunlu Karakoyunlu Devletleri, Ankara 2011, s.180vd.

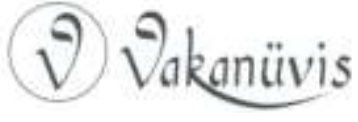


1394 yılında Timur'un tekrar Kara Koyunlu ülkesine girmesi ${ }^{30}$ üzerine Kara Yusuf ve etrafındaki Türkmenler bölgeyi boşaltmışlardır. ${ }^{31}$ Daha önce ele geçiremediği Avnik Kalesi'ni kırk üç gün süren bir kuşatmanın sonucunda Mısır Hoca'dan almayı başarmışırı. ${ }^{32}$ Kalenin komutasını Emir Atlamış'a veren Timur ${ }^{33}$ geri dönerek Van Gölü'nün kuzeyindeki Aladağ'a ${ }^{34}$ gelmiş, burada kısa süre dinlendikten sonra yöreden ayrılmıştır. ${ }^{35}$ Bunu fırsat bilen Kara Yusuf, atalarının yurduna dönerek Erciş'i geri almıştır. ${ }^{36}$

Timur'un Hindistan seferinden dönüp Azerbaycan'a gelmesinden sonra (1399-1400) Kara Yusuf, Van Gölü çevresindeki atalarından kalma yurdunu tahliye ederek Musul'a çekildi ${ }^{37}$ Mısır'a sığınmak istemişse de kabul görmemiştir. Bunun üzerine Sultan Ahmet ile birlikte Osmanlı Sultanı Yıldırım Bayezid'e sığınacaklardır. ${ }^{38}$ Kara Yusuf'un ülkesine dönüşü maceralı geçen birkaç yıldan sonra 1406 yılında olabildi. Kara Yusuf, isabetli tedbiri, hızlı hareketleri ve üstün cesareti sayesinde onları her defasında yenilgiye uğratmayı başardı. Böylece Dımaşk (Şam)'da hapisten kurtulup, ata yurdu Bitlis'e vardı. Hakkari ve Van Gölü çevresinden başlayıp eski Oğuzelleri ile

${ }^{30}$ Timur, Akkoyunlu ve Karakoyunlulara haber gönderip kendisine itaat etmelerini istedi. Karakoyunlulardan olumlu cevapalamayınca bölgeyi istilaya karar verdi. Bkz., Kafalı, a.g.m, s.341.

31 Yezdi, a.g.e., s. 255; Grousset, a.g.e, s. 473vd.

32 Esterebadi, a.g.e., s.424; Yaşar Yücel, Anadolu Beylikleri Hakkında Araştırmalar II, Ankara 1991, s.275; Yaşar Yücel, Kadı Burhaneddin Ahmed ve Devleti, Ankara 1970, s.123.

33 Yezdi, a.g.e., s. 244.

34 Aladağ hakkında geniş bilgi için bkz. Neslihan Durak, "ilhanlılar Döneminde Aladağ Çevresi", I. Uluslararası Ahlat-Avrasya Bilim, Kültür ve Sanat Sempozyumu (23-25 Ağustos 2012), İstanbul 2013, s.242-249.

35 Timur'un bölgedeki diğer faaliyetleri için bkz. Şami, a.g.e., 187-190; Metsobets, a.g.e., s. 35; Yücel, Anadolu Beylikleri Hakkında Araştırmalar II, s.275; Sümer, a.g.e, s.57; "Timur", s.343.

${ }^{36}$ Metsobets, a.g.e., s. 36.

37 Sümer, a.g.e, s.60.

38 ibni Tagrıberdi, a.g.e., s.328; Mehmet Neşri, Kitab-ı Cihannüma I, (nşr. F.R. Unat, M. A. Köymen), Ankara 1995, s.335; İbni Arabşah, Acaibu'I Makddur fi Nevaib-i Timur, (nşr. A.Batur), İstanbul 2012, s.282. Ayrıca bkz. Hoca Sadettin Efendi, Tacü't Tevarih, (nşr., i. Parmaksızoğlu), Ankara 1992, s.229vd; İdris-i Bitlisi, Heşt Bihişt II, (nşr. M. Karataş vd), Kahraman maraş 2007, s.20.

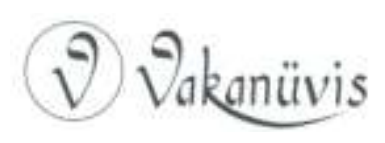


Azerbaycan ülkelerini Timurlulardan kurtarmaya girişti. ${ }^{39}$ Kara Yusuf, her geçen gün daha da güç kazanıyordu. Zira O'nun döndüğünü duyan Türkmen beyleri bayrağı altında toplanmaya başlamışlardı. Hatta Kara Yülük Osman'a haber göndererek birlikte hareket etmelerinin lüzumuna dikkat çektiyse de sonuç alamadı. ${ }^{40}$ Kara Yusuf, Türkmen emirlerini toplayarak onlara, "Atalarımızın ve dedelerimizin izinden gitmemiz gerekir; Yazın Aladağ yaylasına, kışın da Diyarbakır ve Fırat sahili kışlağına gidelim. Çağatay ordusuyla savaşmamız doğru olmaz" deyince Türkmenler, "Eğer Sahib Kıran'ın (Timur) Azerbaycan'da tuttuğu emirler hayatta kalsalardı biz onlarla savaşmazdık. Fakat Mirza Ebu Bekir, onları öldürüp yerlerine getirip yücelttiği rezillerden hiçbir zaman korkmayız" diye karşılık verdiler. Buna memnun olan Kara Yusuf, ${ }^{41}$ Avnik üzerine yürüyerek burayı Doladay'dan almak suretiyle ${ }^{42}$ Bitlis ve Ahlat da dahil olmak üzere Doğu Anadolu'daki ülkesine tamamıyla sahip oldu (1406). ${ }^{43}$

Timur'un ölümünden sonra torunları Ömer ile Ebu Bekir'in birbirleriyle sürtüşmeleri ${ }^{44}$ Kara Yusuf tarafından ziyadesiyle değerlendirildi. 1407 ve 1408 'de Timur'un torunu Ebu Bekir'e karşı kazandığı iki büyük zafer ${ }^{45}$ sonucunda Doğu Anadolu, Azerbaycan ve Irak-ı Acem bölgeleri Kara Koyunlu hâkimiyeti altına alındığı gibi ${ }^{46}$ Kara Koyunlu devleti de kesin olarak kurulmuştur. ${ }^{47}$ Hatta $1407^{\prime}$ lerde yazılmış olduğu tesbit edilen bir Ermeni kaynağı, Kara Yusuf'tan

39 Kırzıoğlu, Kars Tarihi I, s.484.

40 Bkz. Tihrani, a.g.e., s.49.

41 Hasan-ı Rumlu, Ahsenü't Tevarih, (nşr. M. Öztürk), Ankara 2006, s.55.

42 Hasan-ו Rumlu, a.g.e., s.54.

43 Sümer, a.g.e, s.69; İsmail Aka, Iran'da Türkmen Hâkimiyeti (Kara Koyunlular Devri), Ankara 2001, s.4. Bu tarihlerde Timur katından ülkesine dönmekte olan İspanyol elçisi Clavijo, Kara Yusuf'un on bin atlı ile Hoy bölgesini tahrip ettiğini ve Erzincan şehrini de kuşattığından söz etmektedir. Bkz. Ruy Gonzales de Clavijo, Timur'un Hayatı, Kadiz'den Semerkant'a Seyahatler, (nşr. Z. Ertan), İstanbul 2008, s.145.

44 Ayrıntılı bilgi için bkz. Hasan-ı Rumlu, a.g.e., s.36-42.

45 Bu savaşlar hakkında ayrıntılı bilgi için bkz. Hasan-ı Rumlu, a.g.e., s. 55-58 ve 61-65; İsmail Aka, Mirza Şahruh ve Zamanı, Ankara 1994, s.51-55.

46 Şerafhan, a.g.e., s. 435; Colophons of Armenian Manuscripts (1301-1480), (nşr. Avedis K. Sanjian), London 1969, s.131; Peter B. Golden, a.g.e, s.377; Kırzoğlu, Kars Tarihi l, s.484vd.

47 Togan, a.g.e, s.364.

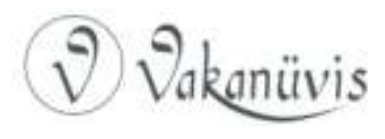


"Türkistan'ın efendisi, mağrur ve dünyada hiç kaybetmemiş, Mardin'den başlayarak Tebriz'e kadar herkese boyun eğdiren..." şeklinde bahsetmektedir. ${ }^{48}$ Timur'un oğullarından Miranşah tutsak alınarak daha sonra öldürülmüştür. ${ }^{49}$ Doğu tarihinin en önemli muharebelerinden biri olan bu muharebe, Timur'un batı tarafındaki fetihlerinin neticesini ortadan kaldırıyor ve ölümünden dört yıl sonra varisleri Batı İran'dan kovulmuş oluyorlardı. ${ }^{50} \mathrm{Bu}$ dönemlerde Kars ili ise Anı vilayeti adıyla Revan ve Eleşkirt çevrelerini de içine alacak şekilde Tebriz'e bağlı kalmıştır. ${ }^{51}$ Nitekim Anı'da XV. asırda kesilmiş olduğu tesbit edilen ancak Kara Koyunlulardan hangi hükümdara ait olduğu bilinmeyen bir bakır paradan bahsedilmektedir. ${ }^{52}$

Zaferden sonra Kara Yusuf, geleneksel olarak yazı geçirmek üzere çok sevdiği Aladağ'a gitmiş, ${ }^{53}$ burada Nevşehir mevkiinde ordusuna bir geçit töreni yaptırdıktan sonra Tebriz'e yönelmiştir. Zira bu sırada Celayirli Ahmet Azerbaycan'ı işgal etmişti. Ağustos 1410'da Tebriz civarında Kara Yusuf bir dönem kader arkadaşlığı yaptığı Ahmet Celayir'i yenerek esir almıştır. Oğlu Pir Budak için Azerbaycan'ı ve büyük oğlu Şah Mehmet için de Irak-ı Arap'ı tefviz ettiğine dair yarlık aldıktan ${ }^{54}$ sonra O'nu Celayirli emirlerinin ısrarı üzerine öldürülmesine

48 Colophons of Armenian Manuscripts (1301-1480), s.129.

49 Ankara Savaşı'nda Timur'a esir düşen Alman asilzadesi Johannes Schiltberger, Kara Yusuf'un Miranşah'ı öldürerek intikam aldığını söyler. Çünkü Kara Yusuf'un kardeşi Musa'yı da Timur'un oğlu Cihangir öldürmüştür. Bkz. Johannes Schiltberger, Türkler ve Tatarlar Arasında (1394-1427), (nşr. Turgut Akpınar), İstanbul 1997, s.86.

50 Grousset, a.g.e, s.498.

51 Kırzıoğlu, Kars Tarihi l, s.485.

52 Paranın basıldığı mahallin Ani'den yalnız $3 \mathrm{~km}$ uzaklıkta bulunan Mahazpert kalesi olması muhtemeldir. Bkz. W. Barthold, "Ani", IA I, s.436.

53 Sümer, a.g.e, s.77.

54 Sultan Ahmed Celayiri'nin ceddi büyük Şeyh Hasan'ın validesi İlhaniye hükümdarı Argun Han'ın kızı idi; bundan dolayı İlhanilerin inkırazından sonra bu rabıta dolayısıyla hükümeti meşru sayıldı. Celayiriye hükümdarının muvafakati olmadan onun idaresi altında bulunan bir aşiret reisinin hükümet kurması mümkün olamazdı. Bundan dolayı Kara Yusuf Bey, Sultan Ahmed'in manevi evlat olarak kabul ettiği Pir Budak'ı hükümdar ilan ettirmek suretiyle saltanatı elde etmiş oluyordu. Kara Yusuf Bey, daha sonra Sultan Ahmed'i esir edip, Azerbaycan hükümetini altın damgalı menşurla istihsal ettikten sonra efendisini öldürmüş ve bu sayede onun memleketlerinin çoğuna sahip olmuştu.

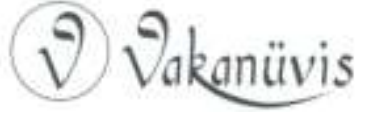


izin vermiştir. ${ }^{55} 1411$ yılının sonlarını Aladağ'da geçirmiş olan Kara Yusuf, 1412 yılı başlarında Muş sahrasına gelip ${ }^{56}$ padişahlığını ilan ettiği oğlu Pir Budak için büyük bir toy vermiştir. ${ }^{57}$

Türkmen Yusuf Bey'in önce Timurlu mirzalarını yenmek ve ardından Celayirli Ahmet'i ortadan kaldırmak suretiyle Azerbaycan'a hâkim olunca, Timurluların tehlikeli bir komşusu haline gelmişti. ${ }^{58}$ Şahruh ise doğuda durumunu sağlama almış ve artık Kara Koyunlularla yakından ilgilenmenin zamanı geldiğini düşünmeye başlamıştı. Evvela Kara Yusuf tarafından öldürülen abisi Miranşah'ın intikamının alınması gerekiyordu. Diğer taraftan İran Moğollarının merkezi durumundaki bölgenin sembolik önemi vardı. Timur'un Sultaniye'yi fethinden itibaren hanedan İlhanlıların mirasını devraldığı iddiasındaydı. Bu Şahruh için önemliydi. Çünkü kendisi de İlhanlı ünvanlarını benimsemiş ve İran'da Moğol geleneklerini uygulayan Gazan Han'ı taklit ediyordu. Kazvin ve Sultaniye gibi ticari önemi olan şehirleri ise kendi topraklarının bir parçası sayıyordu. ${ }^{59}$ Maksadına savaşmadan ulaşmak isteyen Şahruh, Kara Yusuf'a elçi göndererek kendisine tabi olmasını istemişti. ${ }^{60} \mathrm{Bu}$ girişiminden olumlu bir sonuç alamayan Çağatay hükümdarı genel bir seferberlik ilan ederek hazırlıklara başlamıştır. Ağustos 1420 'de Herat'tan hareket eden Şahruh, yolu üzerindeki önemli zatların türbelerini ziyaret ediyor, bizzat istihareye yatıp dua ettiği gibi hafızlardan 12 bin kere Fetih suresini okumalarını dahi

Bu konu hakkında bkz. Hasan-ı Rumlu, a.g.e., s. 84; i. H. Uzunçarşılı, Osmanlı Devlet Teşkilatına Medhal, Ankara 1998, s.268.

55 Hasan-I Rumlu, a.g.e., s. 83vd.

${ }^{56}$ Hasan-ı Rumlu bu toyun Diyarbakır'da tertip edildiğini belirtmektedir. Hasan-ı Rumlu, a.g.e., s.101.

${ }^{57}$ Cafer b. Muhammed el-Hüseyni, Tarih-i Kebir (Tevarih-i Enbiya ve Müluk), ( nşr. ì. Aka), Ankara 2011, s.84. Kara Koyunlu devlet teşkilatı ve hükümdarlık alametleri hakkında geniş bilgi için bkz. i. H.Uzunçarşılı, Osmanlı Devlet Teşkilatına Medhal, s.268-288.

58 Aka, Iran'da Türkmen Hâkimiyeti, s.13.

59 B. Forbes Manz, Timurlu Iranı'nda iktidar, Siyaset ve Din, (nşr. Dilek Şendil), İstanbul 2013, s.41vd.

60 Sümer, a.g.e, s.105. Ancak Memluk tarihçileri ise Şahruh'un, Miranşah'ın diyetini ve kendi adına sikke kestirilip, hutbe okutmasını istediğini kaydederler. Bkz. Aka, Iran'da Türkmen Hâkimiyeti, s.13.

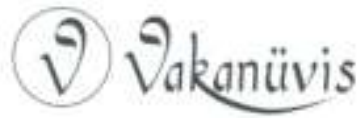


istemişti. Timurlu tarihçilerin verdiği bilgilere göre Şahruh ordusunun büyüklüğüne rağmen zaferden pek ümitli değildi. ${ }^{61}$

Bölgede tek hâkim durumuna yükselen Kara Yusuf, bu duruma son vermek isteyen Şahruh'un karşısına çıkmaya hazırlanırken Tebriz yakınlarında, (13 Kasım 1420) Saidabad ${ }^{62}$ adı verilen bir köyde vefat edecektir. ${ }^{63}$ Kara Yusuf'un ölümü Şahruh'u büyük bir düşmandan kurtarmıştı. Ancak belirli bir düşmana karşı ezici bir zafer kazanma olsılığını kaybetmesine de yol açmıştı. Karşısında teslim alacağı Kara Koyunlu şehzadeleri ile bölgesel bir takım emirlikler kalmıştı. Karabağ'da kışladığı sırada Şahruh'un katına bölgenin yerel hâkimleri ya da elçileri armağanlar ile gelmeye başladılar. ${ }^{64}$ Bunların arasında Kara Yülük Osman Bey'in oğulları Ali ve Bayezid ile diğer Akkoyunlu beyleri de vardı. ${ }^{65}$

Kara Koyunlu emirlerinin ittifakı ile babasının yerine geçen İskender Mirza ise bir taraftan Şahruh'a itaat eden emirleri yola getirmeye çalışırken ${ }^{66}$, diğer taraftan Mardin'e saldıran Kara Yülük üzerine sefer hazırlıkları içerisindeydi. Mart 1421'de Kara Yülük'ü Şeyh Kendi adı verilen yerde yenerek Şahruh karşısına çıkmadan durumunu güçlendirmişti. Diğer taraftan Kara Yusuf'un oğullarından İspend elçi göndererek Şahruh'a tabiiyetini bildirmişti. Ancak Şahruh onun samimi olduğuna inanmayarak, Bayezid kalesi üzerine yürüyerek kaleyi kuşattı. Teslim çağrısına olumlu cevap alamayınca şiddetli bir hücumla kaleyi almayı başardı. Kara Yusuf'un Şahruh üzerine giderken zahireyi ve değerli eşyalarını buraya bırakmış olması, Timurlu hükümdarına önemli miktarda ganimet sağlamıştı. Bu arada kalede bulunan i̇spend ise Muş yazısına çekilmişti. Üzerine kuvvet gönderilmesi üzerine ağırlıklarını

61 Aka, Mirza Şahruh..., s.117vd.

62 Sultaniye-Tebriz yolu üzerinde Ucan'a 4 fersah uzaklıkta bulunan bir köy. Bkz. elHüseyni, a.g.e., s. 84.

63 Devletşah III, s.457; İdris-i Bitlisi, a.g.e., II, s.422; Metsobets, a.g.e., s.65; Hasan-I Rumlu, a.g.e., s.127; Sümer, a.g.e, s.110; i. H.Uzunçarşılı, Anadolu Beylikleri..., s.182; Jakob Phılıpp Fallmerayer, Trabzon Imparatorluğunun Tarihi, (nşr. C. Yavuz vd), Ankara 2011, s. 229.

64 Şerefhan, a.g.e., s.437; Hasan-ı Rumlu, a.g.e., s.136; Manz, a.g.e, s.43.

65

66

Tihrani, a.g.e., s. 62; Hasan-I Rumlu, a.g.e., s. 138.

Colophons of Armenian Manuscripts (1301-1480), s.174; Tıhrani, a.g.e., 68vd.

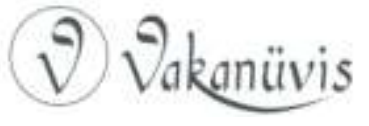


bırakarak Amid (Diyarbakır)'e yönelmiş ve kardeşi i̇skender'e katılmıştır. ${ }^{67}$ Buradan Aladağ'a (Abaka Sarayı) gelen Şahruh, Van Gölü Havzası'na inerek Erciş, Adilcevaz ve Ahlat kalelerini teslim aldı. ${ }^{68}$ VanHakkari emiri İzzeddin Şir oğlu Melik Muhammed, Bitlis emiri Şemseddin ve Muş kalesi hâkimi Emir Abdurrahman'da bizzat gelerek tabiyetlerini bildirdiler. ${ }^{69} \mathrm{Bu}$ duruma memnun olan Şahruh Kara Koyunlu Türkmenleri üzerine kuvvetler göndererek Tebriz'e dönmeye karar verdi. Ancak bu esnada İskender ve İspend mirzaların kuvvetler toplayarak Ahlat ve Adilcevaz civarına geldiklerini öğrendi. ${ }^{70}$

Yakın zamanda Şahruh'un yanına gelmiş olan Akkoyunlu Kara Yülük ise Kara Yusuf'un oğullarının tamamen ortadan kaldırılmadıkça bu memlekette düzenin kurulamayacağını telkin ederek Kara Koyunlularla bir muharebenin kaçınılmazlığını tekrarlayıp duruyordu. ${ }^{71}$ Bu sıralarda Kara Koyunlu şehzadelerinden birkaç defa elçiler gelip barış istemişlerse de kendisini kuvvetli hisseden Şahruh bunları geri çevirmiştir. Başka şanslarının kalmadığını gören Kara Koyunlular ise Eleşkirt tarafına gelerek muharebe hazırlıklarına başlamışlardır. Eleşkirt civarında Altın Yahşi (Bahşi) adı verilen bir yerde ağırlıklarını bırakarak etrafını hendekle çevirdiler. ${ }^{72}$ Ordu ise biraz ileriye giderek savaş düzeni aldı. Ancak Kara Koyunlu Türkmenleri için büyük bir problem vardı. O da Şahruh'un ordusundaki fillerdi. Çünkü Türkmen atları daha önce fille karşılaşmamıştı. Bu sorunu çözmek için belki dünya harp tarihinde ilk defa uygulanacak olan bir yöntem geliştirdiler. Türkmenler büyük öküzler üzerine saman çuvalları ya da ağaç parçaları koyarak file benzetmeye çalıştılar. Çamurdan fil heykelleri yaparak üzerlerine askerler yerleştirildi. Daha sonra atlar bunun üzerine sürülerek alıştırılmaya çalışıldı. ${ }^{73}$

\footnotetext{
67 Tihrani, a.g.e., s. 61.

68 el- Hüseyni, a.g.e., s. 86.

69 Şerafhan, a.g.e., s.109; Sümer, "Ahlat Şehri ve Ahlatşahlar", s.462.

70 Hasan-ı Rumlu, a.g.e., s.138; el-Hüseyni, a.g.e., s.87; Sümer, a.g.e, s.120; Aka, Mirza Şahruh ..., s.123.

71 Hasan-ı Rumlu, s.139; i. Aka, Iran'da Türkmen Hâkimiyeti, s.17.

72 Ebu Bekr-i Tıhraniye göre burası Aladağ civarında Ağadeve denilen bir mevkiidir. Bkz. Tıhrani, a.g.e., s. 62; Ayrıca bkz. Hasan-ı Rumlu, a.g.e., s. 139.

${ }^{73}$ Hasan-ı Rumlu, a.g.e., s. 139vd.
}

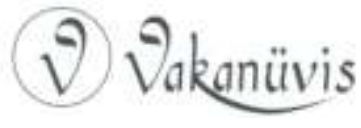


Timurlular ile Kara Koyunlu ordusu nihayet 30 Temmuz 1421 tarihinde Eleşkirt Ovası'nda karşı karşıya geldi. Kara Koyunlu ordusunun sağ kolunda Sa'dlu oymağından Pir Mihmad Bey, merkezde Mirza İskender, sol kolda İspend Mirza ile Bayram Bey ve oğlu Şehsuvar ile Alpagut oymağından Korkan ve Sorkan Beyleri bulunmaktaydı. Çağatay ordusuna gelince, sağ kolda Fars valisi ve Şahruh'un oğlu İbrahim Sultan, Isfahan hâkimi Ömer Şey oğlu Rüstem, Emir İbrahim Cakü, Emir Lokman-ı Barlas, Emir Mihrab-ı Tarhan, sol kolda ise Emir İbrahim, Emir Cihanşah, Emir Alauddin Alige ve Akkoyunlu lideri Kara Yülük Osman mevki almışlardı. ${ }^{74}$ Şahruh ise merkezde yer almıştı. Kara Koyunluların önlem almaya çalıştıkları filler ise ordunun önünde bir kale duvarı görevini yaparken hemen arkalarında okçu yayalar konuşlanmıştı. ${ }^{75}$

Muharebenin ilk günü taraflar birbirlerini denemişlerdir. Özellikle üçüncü gün Türkmenler Timurlu ordusunun karargâhına kadar sokularak deve katarlarını ele geçirmeye başlamışlardır. İskender Mirza bizzat savaşa dâhil olarak Timurlu ordusundaki fillerin hortumlarını kesmiş ve onları işe yaramaz hale getirmiştir. ${ }^{76} \mathrm{Bu}$ sırada Emir Şah Melik bir hileye başvurarak, İspend Mirza'nın tutsak alındığını duyurmuştur. ${ }^{77} \mathrm{Bu}$ Türkmen ordusunda moral bozukluğu yarattığının yanında Timurluların kalabalık oluşunun da etkisiyle Kara Koyunlular, önemli sayıda beylerini de esir vererek savaş alanını terke mecbur kalmşlardır. ${ }^{78}$

Bu zafer vesilesiyle Şahruh fetihnameler yazılmasını buyurmuştur. Bölgeden ayrılmadan evvel Azrbayacan ve çevresinin yönetimini oğullarına ve beylerine teklif etmişse de İskender'in gazabından çekindikleri için hiç kimse buna yanaşmamıştır. ${ }^{79}$ Dönüşü sırasında esir edilmiş Türkmenlerin perişan halini görerek tarihta benzerine pek

75

76

77

79

Tihrani, a.g.e., s.62; Hasan-ı Rumlu, a.g.e., s.140; el- Hüseyni, a.g.e., s. 87.

Sümer, a.g.e, s.121.

Hasan-ı Rumlu, a.g.e., s.143.

Hasan-I Rumlu, a.g.e., s.144.

Aka, Mirza Şahruh..., s.124vd.

Devletşah III, s. 457; Aka, Iran'da Türkmen Hâkimiyeti, s.18.

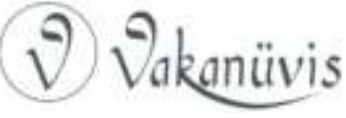


rastlanılmayan bir hareketle onların serbest bırakılmasını istemiştir. ${ }^{80}$ Akkoyunlu lideri Kara Yülük Osman ise savaşın kazanılmasında önemli bir rol oynamıştı. Kadim düşmanları kısa süreli de olsa Doğu Anadolu'dan uzaklaştırılmıştı. Gösterdiği yararlıktan dolayı Şahruh tarafından Doğu Anadolu'da serbest hareket etme yetkisini alarak kısa süre içinde Karakoyunlu şehir ve kalelerini ele geçirmiş ve aile üyelerine paylaştırmıştır. ${ }^{81}$

İskender Mirza, Şahruh'un ülkesine dönmesinden sonra Van Gölü çevresindeki yurtlarına yeniden sahip olabilmek için harekete geçti. Kara Yülük Osman ile hareket edip Şahruh'un tarafına geçen Bitlis, Ahlat, Van ve Vastan (Gevaş) Emirlerini kendi tarafına çağırdı. Bunu sağlayabilmek için de Şeyh Hasan Beğ'i aracı yapan İskender Mirza, emirleri kuvvetleriyle birlikte Aladağ'da toplamayı başardı. Buradan Bingöl yaylağına avlanmayı bahane ederek gelen Kara Koyunlu hükümdarı bu vesileyle onları tutukladı. ${ }^{82}$ Akabinde Ahlat ve Bitlis hakimi Emir Şemseddin'i Ahlat'ta maiyetindeki pek çok kişiyle birlikte öldürtmüştür (1423). ${ }^{83}$

80 Sümer, a.g.e, s.123.

${ }^{81}$ Tihrani, a.g.e., s.65vd; Hasan-ו Rumlu, a.g.e., s.146vd.

${ }^{82}$ Tihrani, a.g.e., s.68vd; Hasan-ı Rumlu, a.g.e., s 146; Colophons of Armenian Manuscripts (1301-1480), s.174.

${ }^{83}$ Tıhrani, s.68vd; F. Sümer, Kara Koyunlular, s.125.

${ }^{83}$ Tıhrani, a.g.e., s.70; Colophons of Armenian Manuscripts (1301-1480), s.174; Hrand

D. Andreasyan, "XIV ve XV. Yüzyıl Türk Tarihine Ait Kronojiler ve Kolofonlar", i.Ü.E.F.T.E.D., III/3, İstanbul 1972, s.108; Sümer, "Ahlat Şehri ve Ahlatşahlar", s.463. Şerefname'de anlatılan bir rivayete göre, Emir Şemseddin'in eşi yani İskender'in kızkardeşi bir Türkmen kızı olduğundan yetişme şartları ve tabiatının gereği olarak ata binmeye, değnek oyunu oynamaya (çevgan), ok atmaya ve meclislere katılmaya heves ederdi. Bu hareketleri Emir Şemseddin tarafından hoş karşılanmamıştı. İkaz edilmesine rağmen aynı davranışlarına devam etmesi üzerine Emir, eşine şiddet uygulayarak onun bir dişini kırmıştır. Kara Yusuf'un kızı, kırık dişini yazdığı nameyle birlikte Erciş'te bulunan abisi i̇skender'e göndermiştir. Bunun üzerine Mirza İskender, Emir Şemseddin'in Ahlat'a gelmesini fırsat bilerek ani bir baskınla onu öldürmüştür. Ancak Şeref Han bu rivayete pek de itibar etmemektedir. O'na göre İskender'in Emir Şemseddin'i öldürmesinin asıl sebebi Bitlis Emirinin Şahruh'un bölgeye intikaliyle birlikte hemen O'na itaat etmesiydi. Bkz. Şerefhan, a.g.e., s.440.

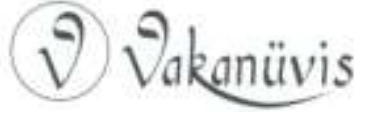


İskender'in tüm faaliyetleri ve ülkesinde yeniden birliği sağlamış olması Şahruh'un ikinci defa Azerbaycan seferine çıkmasına sebep oldu. İskender Mirza idaresindeki Kara Koyunlu ordusu Selmas ${ }^{84}$ Meydan Muharebesi'nde Şahruh'a yenildi (1429). ${ }^{85}$ Timurlular tarafından takip edilen İskender önce Erciş'e, daha sonra da Erzurum tarafına çekildi. Şahruh'un ülkesine avdetinden sonra İskender Mirza yeniden ülkesine hâkim olmak için mücadeleye girişti. ${ }^{86} 1425$ yılı itibariyle İzzeddin Şir oğullarının idaresi altındaki Van-Hakkâri bölgesinin hâkimiyetini tamamen ele geçirdiği anlaşılan İskender ${ }^{87}$ Şahruh'un tekrar bölgeye gelmesi üzerine bir süre Osmanlı topraklarına sığındıktan sonra tekrar ülkesine dönen İskender, mücadelelerinde bir sonuç alamamış ${ }^{88}$ ve nihayet $1438^{\prime}$ de oğlu tarafından öldürülmüştür. ${ }^{89}$

Sonuç itibariyle Doğu Anadolu'nun hâkimiyeti için Kara Koyunlular ile Timurlular arasındaki bu mücadeleler, Kara Koyunlu mirzaları arasındaki taht mücadeleleri ve nihayet Kara Koyunlu- Akkoyunlu kadim düşmanlığı ${ }^{90}$ bölgenin yağmalanmasına sebep olmuştur. Bu bağlamda bilhassa Eleşkirt Meydan Muharebesi'nin Kara Koyunluların yenilgisiyle neticelenmesi Doğu Anadolu'yu siyasi açıdan bir istikrarsızlığa sürükleyecektir. Çünkü Timurlular kazandıkları zaferlere rağmen Anadolu'da kalıcı bir hâkimiyet tesis etmek niyetinde olmamışlardır. Bunun yerine bölgeyi kendi hâkimiyetlerini tanıyan

${ }^{84}$ Selmas/Salmas yöresi hakkında bkz. Hamd-Allah Müstawfi, The Geographical Part of The Nuzhat-al-Qulub, (nşr. G. Le Strange), London 1919, s.87.

${ }^{85}$ kz. Hoca Sadettin Efendi, a.g.e., II, s.177-180; Hasan-ı Rumlu, a.g.e., s.196-199; Heşt Bihişt II, s.423; Ibni Tagrıberdi, a.g.e., s.471; Aka, Mirza Şahruh ve Zamanı, s.142-145; Andreasyan, a.g.m, s. 109; Metsobets, a.g.e., s. 72; John. E. Woods, 300 Yıllık Türk Imparatorluğu Akkoyunlular, (nşr., S. Özbudun), İstanbul 1993, s.93vd.

${ }^{86}$ idris-i Bitlisi II, s.423; Andreasyan, a.g.m, s.110vd.

${ }^{87}$ Aka, Iran'da Türkmen Hâkimiyeti, s.21.

${ }^{88}$ Bu konu hakkında bkz. el-Hüseyni, a.g.e., s.111vd.

${ }^{89}$ Tıhrani, a.g.e., s. 96vd; Hasan-I Rumlu, a.g.e., 228; el-Hüseyni, a.g.e., s.113vd; Hoca Sadettin Efendi, a.g.e., II, s.201; Mehmet Neşri, a.g.e., s.631.

${ }^{90}$ Nitekim XIV. yüzyılda Erzurum şehrine gelen seyyah ỉbn Battuta, şehrin iki Türkmen grubunun mücadeleleri sonucunda harap olduğunu belirtirken Akkoyunlu-Kara Koyunlu sürtüşmelerini kastetmiştir. Bkz. Ebu Abdullah Muhammed ibn Battuta Tanci, ibn Battuta Seyahatnamesi, (nşr. A. Sait Aykut), İstanbul 2013, s.287.

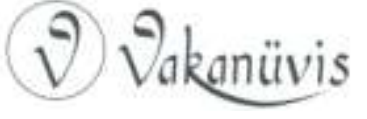


siyasi teşekküller vasıtasıyla yönetmek istemişlerdir. Dolayısıyla Kara Koyunlu Türkmen federasyonu etrafında toplanmış olan Türkmen boy ve oymakları Azerbaycan ve İran coğrafyasına dağıldığı gibi bunun sonucunda özellikle Doğu Anadolu'nun demografik yapısı Türk nüfusu aleyhinde gelişme göstermiştir. Şehirler terk edilmiş ve adeta ıssızlaşmıştır. ${ }^{91}$ Bölgenin Erzurum, Kars, Ani gibi önemli şehirleri bundan ziyadesiyle olumsuz etkilenmiştir.

Kara Koyunlu devleti sahip olduğu konumu sebebiyle XV. yüzyılda Yakındoğunun iki mühim kuvveti olan Mısır Memluklu ve Osmanlı devletine Şahruh'un doğrudan baskı yapmasına mani olmuştur. Bu yüzden Osmanlı, Timur zamanında kurulmuş olan beylikleri rahatça ortadan kaldırmıştır. ${ }^{92}$ Kara Koyunlu Türkmenleri Timurlulara karşı Doğu Anadolu'nun koruyuculuğunu üstlendikleri gibi ${ }^{93}$ Doğu Anadolu, Azerbaycan ve Irak-ı Acem bölgeleri, başlıca Baranlu, Sa'dlu, Baharlu, Duharlu, Karamanlu, Alpagut, Ayinlu, Hacılu, Ağaçeri, Döğer, Bayramlu gibi boy ve oymaklar sayesinde varlıklarını bugün de devam ettirmek üzere Türkleşmesini de sağlanmıştır. ${ }^{94}$

\section{Kaynakça}

Aka, İsmail, “Anadolu'dan İran'a Göçler”, Tarihten Günümüze Türkiran ilişkileri Sempozyumu (16-17 Aralık 2002), Ankara 2003. İsmail, "Timur'un Ölümünden Sonra Doğu Anadolu, Azerbaycan ve Irak-ı Acem'de Hâkimiyet Mücadeleleri", Türk Kültürü Araştırmaları (1984), XXII/1-2,

91 Bu dönemde Doğu Anadolu'dan Azerbaycan ile İran’a yapılan Türkmen göçleri hakkında bkz. İsmail Aka, "Anadolu'dan Iran'a Göçler", Tarihten Günümüze Türk-İran iliş̧kileri Sempozyumu (16-17 Aralık 2002), Ankara 2003, s.57-63.

92 Sümer, a.g.e, s.76,77.

93 Enver Konukçu, Kara ve Akkoyunluların Yurdunda, i̇stanbul 1993, s.7vd.

94 Aka, "Timur'un Ölümünden Sonra Doğu Anadolu, Azerbaycan ve Irak-ı Acem'de Hâkimiyet Mücadeleleri", Türk Kültürü Araştırmaları (1984), XXII/1-2, s.66; Aka, Mirza Şahruh...,s.55; Aka, Iran'da Türkmen Hâkimiyeti, s. 8; Z. V. Togan, "Azerbaycan", IA II, s.111vd.

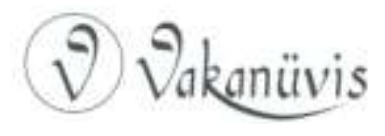


Ankara 2001.

İsmail, Iran'da Türkmen Hâkimiyeti (Kara Koyunlular Devri), , İsmail, Mirza Şahruh ve Zamanı, Ankara1994. İsmail, Timur ve Devleti, Ankara 1991.

Andreasyan, Hrant D., "XIV ve XV. Yüzyıl Türk Tarihine Ait Kronojiler ve Kolofonlar", i.Ü.E.F.T.E.D., III/3, 1972.

Arabşah, İbni, Acaibu'I Makddur fi Nevaib-i Timur, (nşr. A.Batur), İstanbul 2012.

Atsız, Üç Osmanlı Tarihi (Oruç Beğ Tarihi, Dastan ve Tevarih-i Al-i Osman, Behcetü't Tevarih), İstanbul 2013.

Barthold, W., "Ani", iA, I.

Bitlisi, İdris-i, Heşt Bihişt II, (nşr. M. Karataş vd), Kahraman Maraş 2007.

Clavijo, Ruy Gonzales de, Timur'un Hayatı, Kadiz'den Semerkant'a Seyahatler, (nşr. Z. Ertan), i̇stanbul 2008.

Colophons of Armenian Manuscripts (1301-1480), (nşr. Avedis K. Sanjian), London 1969.

Devletşah, Tezkire-i Devletşah III, (nşr. Necati Lügal), Ankara 1987.

Durak, Neslihan, "ilhanlılar Döneminde Aladağ Çevresi", I. Uluslararası Ahlat-Avrasya Bilim, Kültür ve Sanat Sempozyumu (23-25 Ağustos 2012), İstanbul 2013.

El-Hüseyni, Cafer b. Muhammed, Tarih-i Kebir (Tevarih-i Enbiya ve Müluk), ( nşr., i. Aka), Ankara 2011.

Esterebadi, Aziz b. Erdeşir, Bezm ü Rezm, (nşr. Mürsel Öztürk), Ankara 1990.

Fallmerayer, Jakob Phılıpp, Trabzon Imparatorluğunun Tarihi, (nşr. C. Yavuz vd), Ankara 2011.

Golden, Peter B., Türk Halkları Tarihine Giriş, (nşr. O. Karatay), İstanbul 2012.

Grousset, Rene, Bozkır Imparatorluğu (Attila, Cengiz Han, Timur), (nşr. M. Reşat Uzmen, İstanbul 2010.

Gündüz, Tufan, Bozkırın Efendileri (Türkmenler Üzerine Makaleler), İstanbul 2009.

Hoca Sadettin Efendi, Tacü't Tevarih, (nşr., ì. Parmaksızoğlu), Ankara 1992.

Kafalı, Mustafa, "Timur", IA, XII.

Kırzıoğlu, M. Fahrettin, Dede Korkut Oğuznameleri I. Kitap, İstanbul 1952.

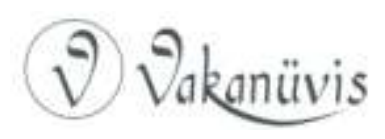


M. Fahrettin, Kars Tarihi I, İstanbul 1953.

Konukçu, Enver, "Kara Koyunlular'ın Avnik Kalesi", Ismail Aka Armağanı, İzmir 1999. 1993.

, Enver, Kara ve Akkoyunluların Yurdunda, İstanbul

Manz, B. Forbes, Timurlu Iranı'nda iktidar, Siyaset ve Din, (nşr. Dilek Şendil), İstanbul 2013.

Metsobets, T'ovma, The History of Tamerlane and His Successors, (nşr. R. Bedrosian), New York 1987.

Müstawfi, Hamd-Allah, The Geographical Part of The Nuzhat-alQulub, (nşr. G. Le Strange), London 1919.

Neşri, Mehmet, Kitab-ı Cihannüma I-II, (nşr. F.R. Unat, M. A. Köymen), Ankara 1995.

Rumlu, Hasan, Ahsenü't Tevarih, (nşr. M. Öztürk), Ankara 2006.

Scihiltberger, Johannes, Türkler ve Tatarlar Arasında (1394-1427), (nşr. Turgut Akpınar), İstanbul 1997.

Spuler, Bertold, Iran Moğolları (Syaset, Idare ve Kültür, IIhanlılar Devri 1220-1350), (nşr. C. Köprülü), Ankara 2011.

Sümer, Faruk, "Ahlat Şehri ve Ahlatşahlar", Belleten, L/297 (1986). , Faruk, "Doğu Anadolu'da Moğol ve Türkmen Devirlerine Ait Bazı Tarihi Yapılar Hakkında Düşünceler", Belleten, LIV/210 ( Ağustos 1990).

, Faruk, Kara Koyunlular, Ankara 1992.

, Faruk, "Anadolu'da Moğollar", SAD I, Ankara 1970.

Şami, Nizamüddin, Zafername, (nşr. Necati Lugal), Ankara 1987.

Şerefhan, Şerefname, (nşr. M. Emin Bozarslan), ìstanbul 1990.

Tagrıberdi, İbn, en-Nücum'z-Zahire (Parlayan Yıldızlar), (nşr. Ahsen Batur), ìstanbul 2013.

Tanci, Ebu Abdullah Muhammed ibn Battuta, ibn Battuta Seyahatnamesi, (nşr. A. Sait Aykut), İstanbul 2013, s.287.

Tihrani, Ebu Bekr-i, Kitab-ı Diyarbekriyye, (nşr. Mürsel Öztürk), Ankara 2001.

Togan, A. Z.Velidi, Umumi Türk Tarihi'ne Giriş I, İstanbul 1981. , Z.Velidi., "Azerbaycan", iA, II.

Uzunçarşılı, i. Hakkı, Anadolu Beylikler ve Akkoyunlu Karakoyunlu Devletleri, Ankara 2011.

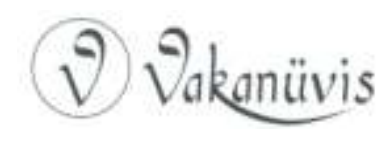


Ankara 1998.

i. Hakkı, Osmanlı Devlet Teşkilatına Medhal,

Woods, John. E., 300 Yıllık Türk Imparatorluğu Akkoyunlular, (nşr., S. Özbudun), İstanbul 1993.

Yezidi, Şerefüddin Ali, Emir Timur (Zafername), (nşr. Ahsen Batur), İstanbul 2013.

Yıldız, H. Dursun, Makaleler III, (nşr. E. S. Yalçın vd), Ankara 2007.

Yinanç, Refet, Dulkadir Beyliği, Ankara 1989.

Yücel, Yaşar, Anadolu Beylikleri Hakkında Araştırmalar II, Ankara 1991.

, Yaşar, Kadı Burhaneddin Ahmed ve Devleti, Ankara 1970. , Yaşar, Timur'un Ortadoğu-Anadolu Seferleri ve Sonuçları (1393-1402), Ankara 1989. 